NASA/TM-1998-206558

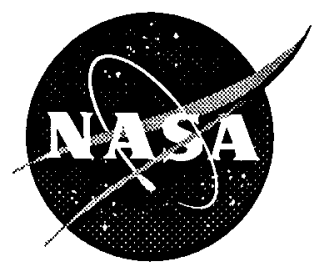

\title{
Initial Flight Test Evaluation of the F-15 ACTIVE Axisymmetric Vectoring Nozzle Performance
}

John S. Orme

Dryden Flight Research Center

Edwards, California

Ross Hathaway

Analytical Services \& Materials

Edwards, California

Michael D. Ferguson

United Technologies Corporation

Pratt \& Whitney

West Palm Beach, Florida

National Aeronautics and

Space Administration

Dryden Flight Research Center

Edwards, California 93523-0273 


\section{NOTICE}

Use of trade names or names of manufacturers in this document does not constitute an official endorsement of such products or manufacturers, either expressed or implied, by the National Aeronautics and Space Administration.

Available from the following:

NASA Center for AeroSpace Information (CASI)

7121 Standard Drive

Hanover, MD 21076-1320

(301) 621-0390
National Technical Information Service (NTIS) 5285 Port Royal Road

Springfield, VA 22161-2171

(703) $487-4650$ 


\title{
INITIAL FLIGHT TEST EVALUATION OF THE F-15 ACTIVE AXISYMMETRIC VECTORING NOZZLE PERFORMANCE
}

\author{
John S. Orme* \\ NASA Dryden Flight Research Center \\ Edwards, CA \\ Ross Hathaway ${ }^{\dagger}$ \\ Analytical Services \& Materials \\ Edwards, CA \\ Michael D. Ferguson \\ United Technologies Corporation \\ Pratt \& Whitney \\ West Palm Beach, FL
}

\begin{abstract}
A full envelope database of a thrust-vectoring axisymmetric nozzle performance for the Pratt \& Whitney Pitch/Yaw Balance Beam Nozzle (P/YBBN) is being developed using the F-15 Advanced Control Technology for Integrated Vehicles (ACTIVE) aircraft. At this time, flight research has been completed for steady-state pitch vector angles up to $20^{\circ}$ at an altitude of $30,000 \mathrm{ft}$ from low power settings to maximum afterburner power. The nozzle performance database includes vector forces, internal nozzle pressures, and temperatures all of which can be used for regression analysis modeling. The database was used to substantiate a set of nozzle performance data from wind tunnel testing and computational fluid dynamic analyses. Findings from initial flight research at Mach 0.9 and 1.2 are presented in this paper. The results show that vector efficiency is strongly influenced by power setting. A significant discrepancy in nozzle performance has been discovered between predicted and measured results during vectoring.
\end{abstract}

\section{$\underline{\text { Nomenclature }}$}

$\mathrm{A}_{8} \quad$ throat area, $\mathrm{ft}^{2}$

$\mathrm{A}_{9} \quad$ exit area, $\mathrm{ft}^{2}$

* Aerospace Engineer, AIAA member.

Aerospace Engineer.

${ }^{\ddagger}$ Propulsion Engineer, AIAA member.

Copyright (C) 1998 by the American Institute of Aeronautics and Astronautics, Inc. No copyright is asserted in the United States under Title 17, U.S. Code. The U.S. Government has a royalty-free license to exercise all rights under the copyright claimed herein for Governmental purposes. All other rights are reserved by the copyright owner.

\begin{tabular}{|c|c|}
\hline ACTIVE & $\begin{array}{l}\text { Advanced Control Technology for } \\
\text { Integrated Vehicles }\end{array}$ \\
\hline ANOVA & analysis of variation \\
\hline $\mathrm{BBN}$ & balanced beam nozzle \\
\hline CFD & computational fluid dynamics \\
\hline DAG & Dial-A-Gain \\
\hline DFRC & $\begin{array}{l}\text { Dryden Flight Research Center, Edwards, } \\
\text { California }\end{array}$ \\
\hline F-test & $\begin{array}{l}\text { A statistical test for the contribution of the } \\
\text { independent variable in predicting the } \\
\text { dependent variable }\end{array}$ \\
\hline Faero & aerodynamic flap force, $\mathrm{lb}$ \\
\hline$F_{\text {corr }}$ & $\begin{array}{l}\text { regression analysis approach } 2 \text {, force } \\
\text { correction, } \mathrm{lb}\end{array}$ \\
\hline FCS & flight control system \\
\hline$F d j$ & direct jet force, $\mathrm{lb}$ \\
\hline$F e$ & external force, $\mathrm{lb}$ \\
\hline Fent & entrainment-induced force, $\mathrm{lb}$ \\
\hline$F g r$ & resultant gross thrust, lbs \\
\hline$F i$ & internal force, $l b$ \\
\hline Find & nozzle induced force, $\mathrm{lb}$ \\
\hline$F_{O}$ & nonvectored gross thrust, lb \\
\hline$F v$ & total vector force, $l b$ \\
\hline$F v / F o$ & $\begin{array}{l}\text { vector-to-thrust force ratio, percentage of } \\
\text { nonvector gross thrust }\end{array}$ \\
\hline IDEEC & $\begin{array}{l}\text { improved digital electronic engine } \\
\text { controller }\end{array}$ \\
\hline
\end{tabular}




\begin{tabular}{|c|c|}
\hline IFT & in-flight thrust model \\
\hline IPE & improved performance engine \\
\hline LaRC & $\begin{array}{l}\text { Langley Research Center, Hampton, } \\
\text { Virginia }\end{array}$ \\
\hline $\operatorname{Max}$ & $130^{\circ}$ of power setting \\
\hline Mil & $85^{\circ}$ of power setting \\
\hline MPD & multipurpose display \\
\hline MUX & Military Standard 1553 multiplex databus \\
\hline $\mathrm{NC}$ & nozzle control computer \\
\hline NPR & nozzle pressure ratio \\
\hline OAR & optimum area ratio \\
\hline P-test & $\begin{array}{l}\text { A statistical test for the probability of } \\
\text { being wrong in concluding there is an } \\
\text { association between variables }\end{array}$ \\
\hline $\mathrm{P}_{0}$ & ambient pressure \\
\hline $\mathrm{Pt}_{6}$ & total pressure of engine augmentor, $1 \mathrm{~b} / \mathrm{in}^{2}$ \\
\hline PW & Pratt \& Whitney, West Palm Beach, Florida \\
\hline $\mathrm{P} / \mathrm{YBBN}$ & Pitch/Yaw Balance Beam Nozzle \\
\hline $\mathrm{R}^{2}$ & coefficient of determination \\
\hline S/MTD & $\begin{array}{l}\text { Short Take-Off and Landing/Maneuver } \\
\text { Technology Demonstrator }\end{array}$ \\
\hline sync ring & annular synchronization ring \\
\hline $\mathrm{Tt}_{2}$ & total temperature at engine face, ${ }^{\circ} \mathrm{F}$ \\
\hline USAF & United States Air Force \\
\hline VMSC & vehicle management system computer \\
\hline $2 \mathrm{D}$ & two-dimensional \\
\hline$\delta_{f}$ & force angle, deg \\
\hline$\delta_{m}$ & metal angle, deg \\
\hline$\delta_{p}$ & plume angle, deg \\
\hline$\eta_{v}$ & vector efficiency, percentage of metal angle \\
\hline$\theta_{\text {corr } 1}$ & $\begin{array}{l}\text { regression analysis approach } 1 \text {, angle } \\
\text { correction, deg }\end{array}$ \\
\hline$\theta_{\text {corr } 4}$ & $\begin{array}{l}\text { regression analysis approach } 4 \text {, angle } \\
\text { correction, deg }\end{array}$ \\
\hline$\mu_{f}$ & $\begin{array}{l}\text { regression analysis approach } 3 \text {, vector } \\
\text { force effectiveness, lb }\end{array}$ \\
\hline
\end{tabular}

\section{Introduction}

Future aircraft designers could benefit from the availability of efficient thrust vectoring nozzles.
Because thrust vectoring may efficiently produce pitch and/or yaw forces and moments with relatively less drag than conventional aerodynamic surfaces, vectoring nozzles could augment or possibly replace aerodynamic controls altogether. Thrust vectoring enables potential improvements in aircraft maneuverability by providing aircraft with forces and moments in some regions of the flight envelope that are more effective than aerodynamic surfaces. Additionally, aircraft safety enhancements could be realized with thrust vectoring when vectoring nozzles are used as redundant or backup control effectors to aerodynamic surfaces. Use of trade names or names of manufacturers in this document does not constitute an official endorsement of such products or manufacturers, either expressed or implied, by the National Aeronautics and Space Administration.

\section{Background}

Thrust vectoring aircraft offer numerous advantages over conventionally equipped aircraft, including improved maneuverability, survivability, and aircraft cruise performance. ${ }^{1}$ Many turbofan engines of today's high-performance aircraft include nonvectoring nozzles of axisymmetric design, such as the General Electric F404 and Pratt \& Whitney F100. The performance potential of vectoring axisymmetric nozzles has been investigated and predicted in subscale wind tunnel tests and in analytical studies. ${ }^{2,3,4}$ Ultimately, however, only with the application and validation available from flight tests may the full-scale vectoring nozzle performance potential be realized.

Vectoring additions to the F404 and the F100 engines have been the focus of recent flight research test programs. ${ }^{5,6}$ With the development of the Pitch/Yaw Balance Beam Nozzle (P/YBBN), Pratt \& Whitney (PW) of West Palm Beach, Florida has extended the capabilities of their standard F100 nozzle to include axisymmetric vectoring and independent exit area control. Requiring very few engine changes, the $\mathrm{P} / \mathrm{YBBN}$ mated with an F100 offers up to $20^{\circ}$ of axisymmetric vectoring, and provides for up to $4000 \mathrm{lb}$ vector force, normal to the engine centerline.

To mature vectoring axisymmetric nozzle technology and assess in-flight the operability and performance of the P/YBBN design, two F100-PW-229 engines were modified with the addition of two P/YBBN. The aircraft chosen to host the vectoring propulsion system was the highly modified F-15 ACTIVE (Advanced Control Technology for Integrated Vehicles) vehicle. Flight testing is currently being conducted at the NASA Dryden Flight Research Center (DFRC), Edwards, California. 


\section{ACTIVE Flight Research Program}

The F-15 ACTIVE flight test team consists of an industry and government partnership involving Pratt \& Whitney, Boeing Phantom Works (St. Louis, Missouri), United States Air Force (USAF) Wright Laboratories, and NASA DFRC. Conceived in 1992, the program was designed to mature and evaluate a thrust vectoring system as it is gradually and fully integrated with the advanced aircraft flight control capability unique to the F-15 ACTIVE.

Aircraft modifications required to integrate the $\mathrm{P} / \mathrm{YBBN}$ vectoring system included structural reinforcement and avionics upgrades. Flight clearance was granted after an installed static ground test verified aircraft and vectoring system modifications with the full $4000 \mathrm{lb}$ vector and $20^{\circ}$ of vector angle. This test also provided the first opportunity to evaluate nozzle performance, although nozzle pressure ratios and geometries were far from design operating conditions.

Following the ground tests, the first flight research operation occurred on February 14, 1996. Flight research was divided into two phases: nozzle envelopeexpansion and nozzle performance. During the initial nozzle envelope expansion, operability and compatibility issues of the integrated F-15 ACTIVE vehicle and vectoring system were addressed. Envelopeexpansion cleared nozzle operation to $6.5 \mathrm{~g}$, Mach 2.0, $1600 \mathrm{lb} / \mathrm{ft}^{2}$ dynamic pressure, and $30^{\circ}$ angle of attack, allowing adequate capability to meet the programs research requirements.

One of the program's major flight research objectives is to measure and evaluate thrust vectoring nozzle performance and the potential improvements in aircraft performance. Initial nozzle performance flight data were gathered during the summer and fall of 1996. In-flight nozzle loads were directly measured at the engine mounts using a pioneering approach that significantly aided both the nozzle envelope expansion and research test phases. ${ }^{7}$ In coordination with precisely controlled engine and nozzle configurations, a valuable database is being generated that was never before available. This database can contribute to understanding the capabilities and characteristics of the axisymmetric vectoring P/YBBN. Up to this date, a limited amount of highquality nozzle performance data has been collected at subsonic and supersonic conditions, spanning nozzle pressure ratios from 3.7 to 7.5. Data from Mach 0.9 and an altitude of $30,000 \mathrm{ft}$ is considered as a base-point flight condition for comparison of future data analysis. Results shown in this report highlight the initial findings of the ACTIVE nozzle performance flight testing at Mach 0.9 and 1.2 at an altitude of $30,000 \mathrm{ft}$. A review of critical flight instrumentation, test technique, and planning are also included. To aid the interpretation of the data, a regression analysis technique was applied and vector performance models developed.

\section{Nozzle Performance Flight Test Research Objectives}

Flight research of full-scale axisymmetric nozzle vectoring performance and flight validation of predictive methods are the primary objectives of the ACTIVE nozzle performance testing. The nozzle performance evaluation attempts to identify what influences vectoring efficiency and how measured performance correlates with design tool predictions and wind tunnel results. Areas where predictions fall short of tested nozzle performance are closely examined, to understand the differences and how the design tools may be improved. This understanding is important because it may lead to prediction tool improvements and bring to light the strengths and weaknesses of the P/YBBN design. Table 1 lists the specific flight test research objectives.

Table 1. Nozzle performance flight test research objectives.
A. Identify baseline nozzle performance with
1. NPR sweep at constant altitude
2. Altitude effects at constant Mach number
3. NPR sweep at constant dynamic pressure
B. Identify nozzle performance at reduced area ratio
C. Evaluate and compare yaw nozzle performance with pitch vector
D. Identify nozzle performance at low power settings

The primary influences on nozzle performance for a given area ratio and vector angle configuration are expected to be nozzle pressure ratio, dynamic pressure, and Mach number, based upon data from analytical models and limited wind tunnel testing. The flight test objectives were derived in an attempt to span as large a range as possible for each of these parameters within the cleared portions of the F-15 ACTIVE envelope.

\section{Nozzle Performance Evaluation}

Propulsion system forces and nozzle loads were measured during parametric variations in power setting, Mach number, altitude, pitch vector angle, and area 
ratio. Specific levels of nozzle pressure ratio (NPR) were achieved through selection of the appropriate combination of target power setting, Mach number, and altitude. Exhaust plume angles were determined and compared with the nozzle vector angle. Critical strain gage instrumentation, that measured the engine mount loads and the flexible ACTIVE open-loop flight control architecture to precisely position the nozzle, allowed uniquely valuable data of excellent quality to be gathered during the flight testing.

\section{Validation of CFD and Wind-Tunnel Results}

A computational fluid dynamics (CFD) analysis of the P/YBBN design was accomplished in the development of the full-scale flight test article. CFD predictions of nozzle performance were confirmed with wind tunnel testing of a subscale axisymmetric nozzle. ${ }^{2,3}$ The wind tunnel tests also provided the only insight into expected effects of external airflow over the nozzle. Computational fluid dynamic predictions and subscale model wind tunnel results can be validated with in-flight measures of vector force angles and limited nozzle internal static pressures. Comparisons can be made over a large portion of the ACTIVE flight and engine operating envelope but are limited to the lower NPRs and nozzle configurations that were used during the CFD analysis and wind tunnel testing.

\section{Flight Test Technique}

Before the actual flight test was accomplished and data collected, test techniques and datasets were designed and cleared for flight. Test techniques were developed and dataset verification and validation were accomplished with NASA's piloted aircraft simulation. Dataset verification consisted of checking trims sent from the vehicle management system computer (VMSC) to the flight control system (FCS) to confirm that they produced the desired commands in vector deflection and area ratio. Dataset validation ensured that the nozzle responded to the trims in the expected manner and that the vector forces did not produce unsafe transients in aircraft response.

Datasets were designed to command a pulse in pitch vector waveforms to the left nozzle, and primarily in the negative or trailing-edge-up direction. Most datasets were designed to capture steady-state vectoring data at $-2^{\circ},-4^{\circ},-7^{\circ},-10^{\circ}$, and $-20^{\circ}$ of pitch vector angle. In some cases, particularly at the highest power settings, the nozzle control computer (NC) predicts that $4000 \mathrm{lb}$ of vector force may be exceeded and limits the range of achievable vector metal angle. Additional steady-state data was collected for off-scheduled area ratio during vectoring by overlaying a slow rate square doublet waveform of commanded area ratio trim superimposed on a pulse pitch vector command (fig. 1).

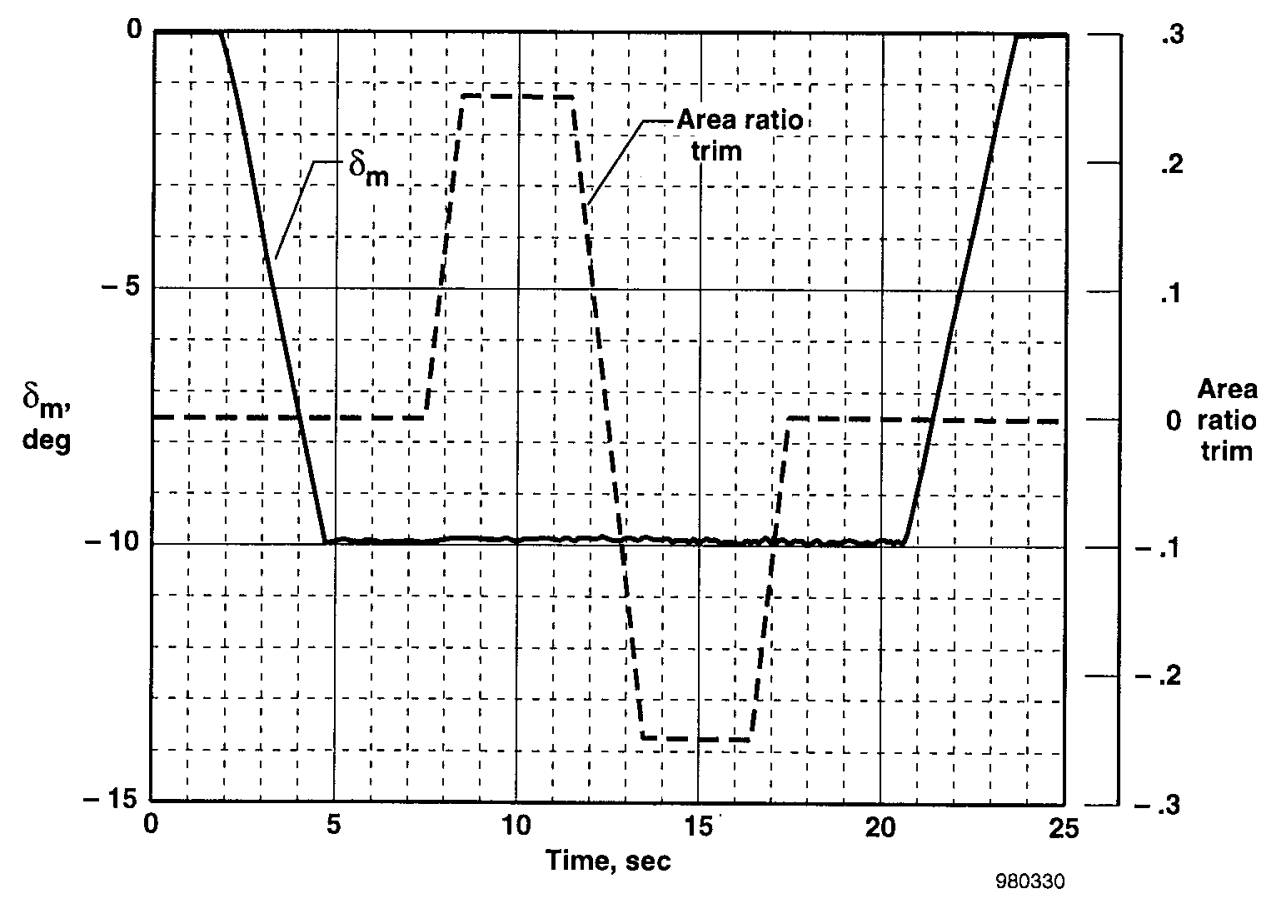

Figure 1. Pitch vector command and area ratio trim dataset waveform. 
Execution of the dataset in flight was typically done during wings-level $1-g$ cruise. All of the data presented in this paper are for single left-hand nozzle only; the right-hand nozzle was not vectored. The pilot was allowed to make small stick and right-engine-throttle adjustments during the tests to maintain conditions, but there was no left-engine throttle movement. If the aircraft excess thrust exceeded that for level flight, a wings-level climb not exceeding $\pm 1000 \mathrm{ft}$ was initiated. To minimize the effects of unsteady external loads, the aircraft speedbrake was not deployed.

\section{Aircraft System And Nozzle Description}

A description of the unique features and capabilities of the ACTIVE system follows. The propulsion system, nozzle control computer and control algorithms, and aircraft measurements are discussed in some detail.

\section{ACTIVE Unique Features and Capabilities}

The test aircraft, NASA 837, is pre-production F-15B number 1, (USAF S/N 71-0290) on loan to NASA from the Air Force. The aircraft is highly modified and is not representative of production F-15 aircraft. It was selected to serve as the research test bed for the ACTIVE program because of the flexibility of its unique quad-redundant, digital, fly-by-wire, flight and propulsion control system. This unique test bed had previously been used to demonstrate two-dimensional
(2D), pitch-vectoring, thrust-reversing nozzles (predecessors to the F-22 2D pitch-vectoring nozzles) as part of the F-15 S/MTD program (Short Take-Off and Landing/Maneuver Technology Demonstrator). ${ }^{8}$ NASA replaced the $2 \mathrm{D}$ pitch-vectoring nozzles with state-ofthe-art axisymmetric pitch and yaw thrust-vectoring nozzles. To support thrust vectoring research in the yaw axis, the aircraft structure has been modified to accommodate $4,000 \mathrm{lb}$ of yaw vector force and $20^{\circ}$ yaw vectoring. Figure 2 summarizes the flight test configuration of the aircraft.

The aircraft is controlled by a quad-redundant, digital, fly-by-wire, FCS. All mechanical linkages between the control stick, rudder pedals, and control surfaces have been removed from the aircraft. The throttles digitally control the engines through the FCS, 1553 Multiplex (MUX) bus, and improved digital electronic engine controllers (IDEECs). No mechanical linkage exists between the throttles and the engines.

The aircraft cockpit closely resembles the F-15E cockpit. Options added to the multipurpose display (MPD) allow the pilot to select and configure the aircraft for testing. Two flight test displays, the Dial-A-Gain (DAG) display and the ACTIVE display, are relevant to the tests described in this paper. The DAG system functions primarily to establish software test limits for the research control law commands from the vehicle management system computer (VMSC). DAG

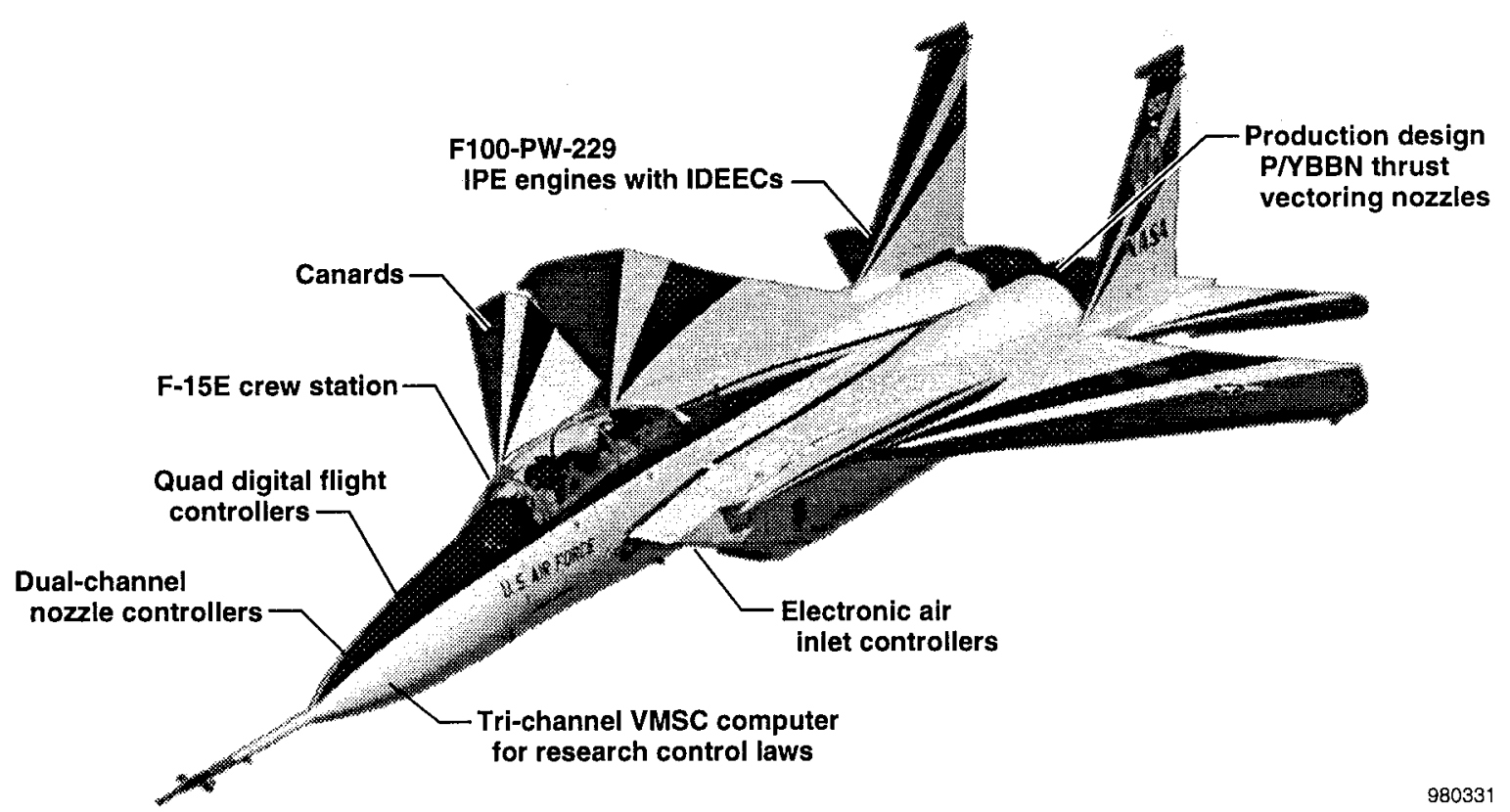

Figure 2. The F-15 ACTIVE vehicle configuration. 
parameters include pitch or yaw thrust vectoring force limits. The ACTIVE display allows the pilot to select 1 of 15 pre-programmed datasets stored in the VMSC. Datasets contain open-loop commands processed in the VMSC and transmitted to the FCS through the MUX bus. Simple reprogramming of the load of the 15 ACTIVE datasets accommodates entirely different test requirements. With the current avionics configuration, nozzle vectoring can only occur when the pilot selects a vector dataset through the ACTIVE cockpit display.

\section{ACTIVE Propulsion System Description}

The ACTIVE propulsion system consists of two F100-PW-229 engines, each equipped with a PW axisymmetric thrust vectoring $\mathrm{P} / \mathrm{YBBN}$ featuring independent exit area control (fig. 3). The F100-PW-229 is an augmented 29,000 lbf thrust class turbofan engine, featuring a three-stage fan and ten-stage compressor, each driven by a two-stage turbine. Only minor engine modifications were required to mount the $\mathrm{P} / \mathrm{YBBN}$ nozzle module.
The F100 balanced beam nozzle (BBN), from which the $\mathrm{P} / \mathrm{YBBN}$ is derived, is of convergent-divergent design. Throat area is controlled by the IDEEC that commands pneumatically driven actuators to achieve nozzle throat areas ranging from 2.9 to $6.5 \mathrm{ft}^{2}$. The $\mathrm{P} / \mathrm{YBBN}$ extends the capabilities of the proven $\mathrm{BBN}$ design to provide mechanical vectoring up to $20^{\circ}$ in any circumferential direction and independent nozzle exitto-throat area ratio modulation from 1.1 to 3 . Because the possibility exists of exceeding the $4000 \mathrm{lb}$ vector force design limitation, limits are imposed on the commanded vector angle. Only three principal additions to the BBN nozzle allow for vectoring and exit area control capability. These additions include: (1) a divergent actuation system that drives (2) an annular synchronization (sync) ring supported and enclosed by (3) a static structure. Three divergent actuators, 16 flaps, and link hardware attach to the sync ring.

Symmetric translation of the three divergent actuators produces changes in area ratio (fig. 4). Coordinated differential positioning of the three divergent actuators

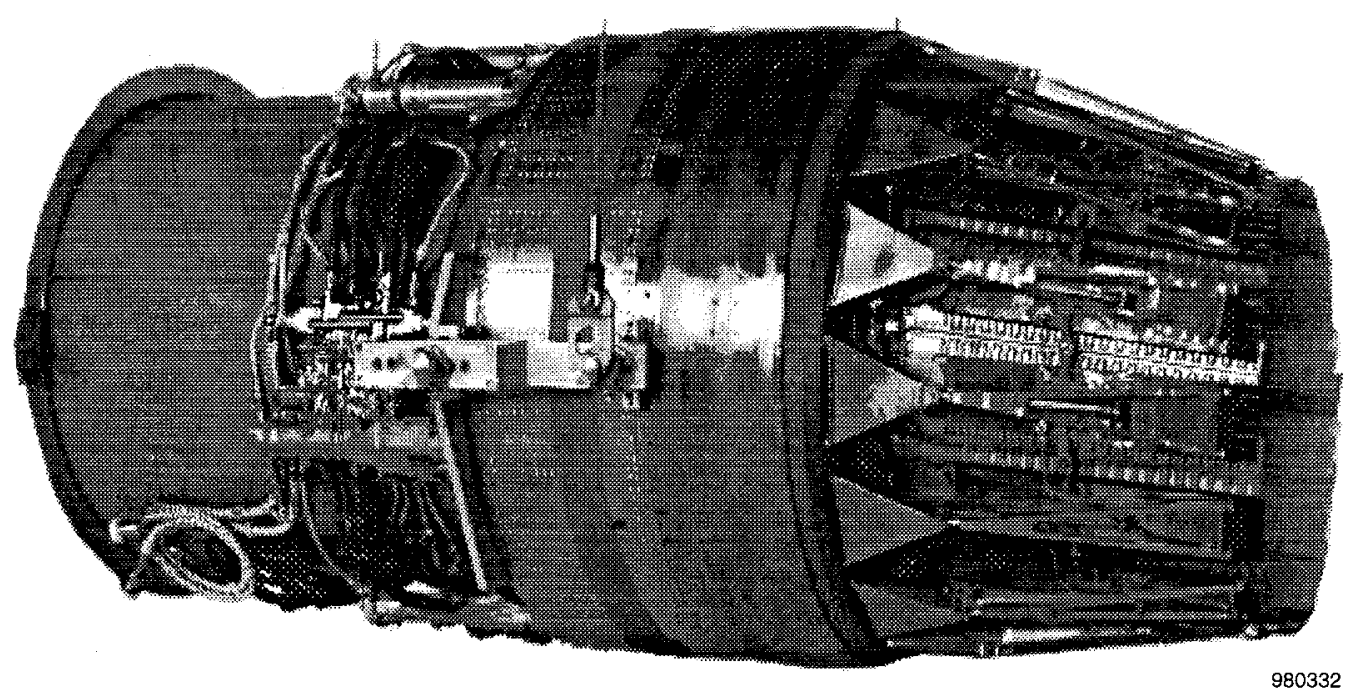

Figure 3. Pitch/Yaw Balance Beam Nozzle module.

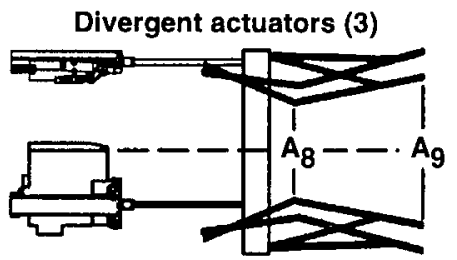

Response to $A_{8}$ modulation

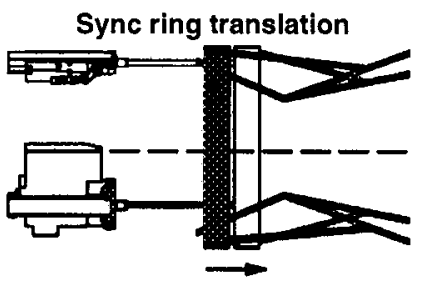

Area ratio modulation

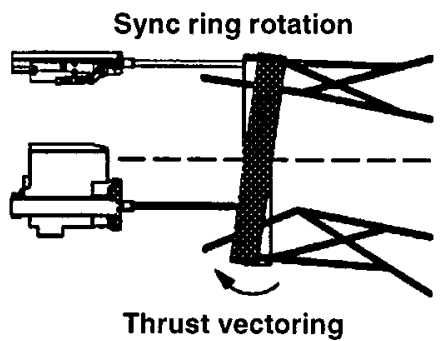

980333

Figure 4. Divergent section motion is dependent upon sync ring position. 
produces changes in vector angle. The actuator motions required to set exit area and thrust vector angle are superimposed over each other. The throat area, area ratio, and vector angle comprise three degrees of freedom for the PYBBN.

\section{Nozzle Control Computer and Control Algorithm}

A nozzle control computer (NC) provides closed-loop positioning of the divergent section of each nozzle. The FCS transfers vector and area ratio modulation commands over the MUX Bus to the NC. The NC translates vector and area ratio commands into requested divergent actuator stroke positions. Before applying any such requests, the NC performs extensive fault detection and accommodation. The NC nominally schedules the divergent actuators to a schedule referred to as the "optimum area ratio" or OAR. Theoretically, with the OAR schedule, the total pressure supplied to the nozzle should be completely expanded to ambient static pressure. The NC does not schedule vector angle, and only commands vectoring when requests are sent from the VMSC, transmitted by the FCS, and received by the NC.

The NC applies software limitations to the vector and area ratio scheduling to prevent potential divergent section hardware damage such as left- and right-nozzle interference. Because neither engine gross thrust or vector forces are directly measured, the $\mathrm{NC}$ possesses an algorithm to estimate both. Based upon its vector force estimate, the NC limits vector force to $4000 \mathrm{lb}$ per nozzle to protect the aircraft, engine, and nozzle structure from overload.

The NC uses a simplified pressure-area gas generator method to calculate engine resultant gross thrust directed along the nozzle centerline. The resultant gross thrust, $F g r$, is determined by taking a gross thrust coefficient scheduled with nozzle pressure ratio (NPR) and multiplying by the estimated total pressure at the nozzle convergent inlet and the effective nozzle throat area. The effective nozzle throat area is derived from the measured physical throat area and compensation for the effect of vectoring on the nozzle discharge coefficient.

Nozzle vector forces and angles are depicted in figure 5 . The total vector force, $F v$, is directed normally to the engine centerline and consists of internal and external forces acting on the nozzle. A direct jet, $F d j$, and a nozzle induced force, Find, comprise the internal force, $F i$. Whereas, an aerodynamic flap, Faero, and an entrainment-induced force, Fent, comprise the external force, $F e$.

The direct jet force term, $F d j$, is determined by multiplying the resultant gross thrust by the sin of the vector metal angle. $F d j$ represents the internal vector force arising from redirecting the engine gross thrust by the vector metal angle, $\delta_{m}$. Under most circumstances the complex flow within the nozzle deviates from the metal angle. The angle at which the flow turns is the plume angle, $\delta_{p}$. To account for the force associated with the difference between turning the flow through the plume and metal angles, the NC models a nozzleinduced force, Find. The induced force phenomenon was observed during static testing of a subscale axisymmetric nozzle in the 16-foot Transonic Wind Tunnel at NASA Langley Research Center (LaRC). ${ }^{2}$ A two-dimensional Euler calculation of the internal nozzle vector forces, $F i$, conducted by $\mathrm{PW}$ was verified with LARC results and then implemented in tabular format into the NC.

In addition to the internally generated forces, the nozzle also generates external forces whenever air flows over the exterior surface of the nozzle. The aerodynamic flap force, Faero, arises from the component of drag

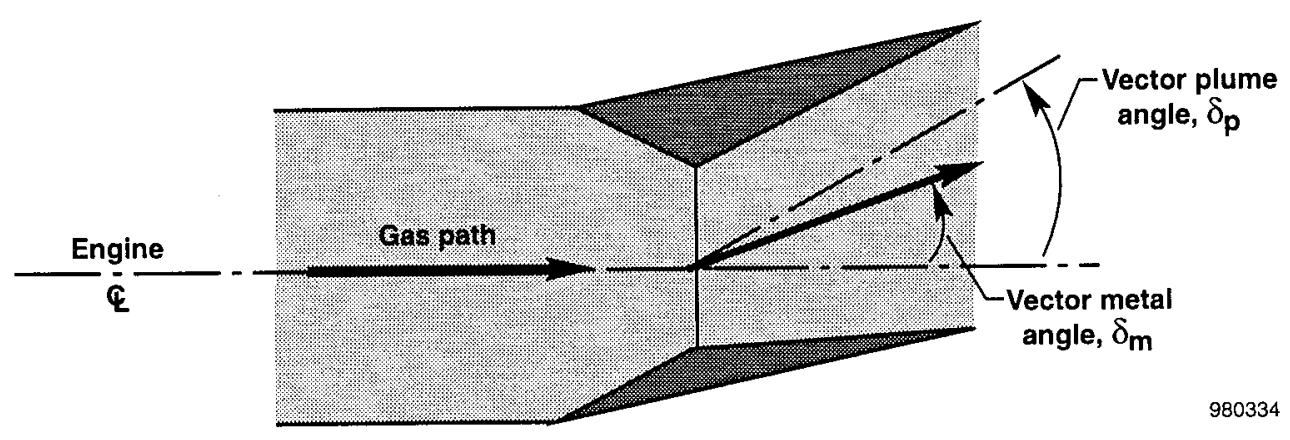

(a) Nozzle vector angle definitions.

Figure 5. Schematic of nozzle vector force components and angles. 


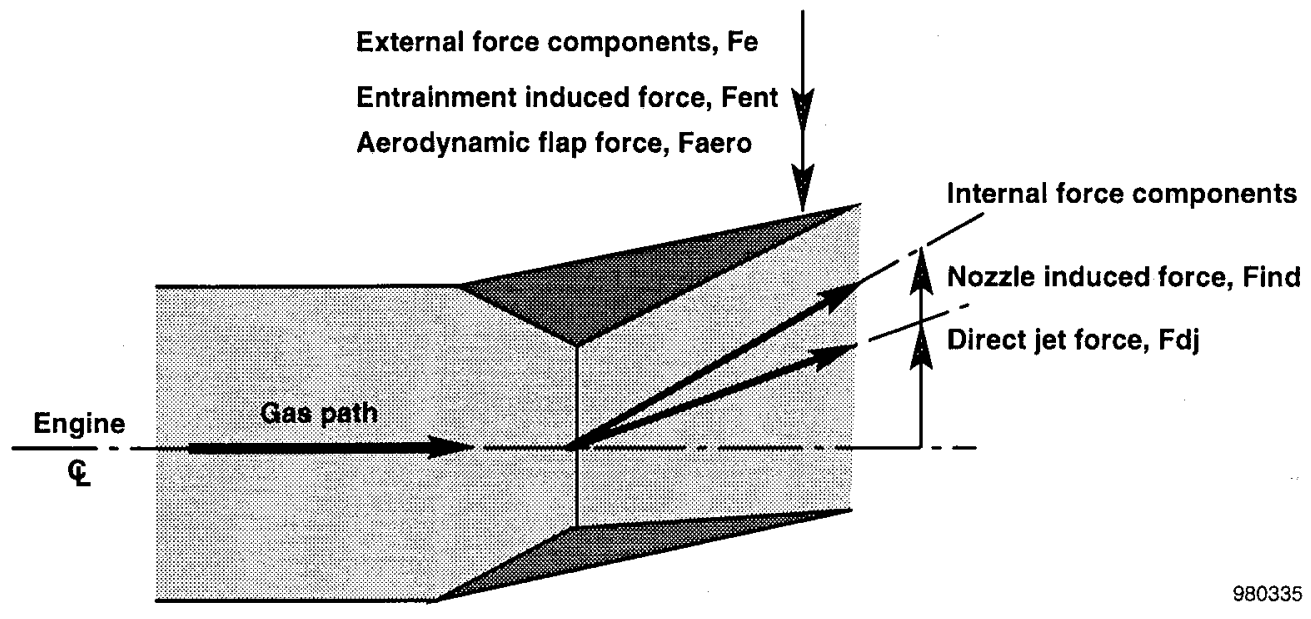

(b) Nozzle vector force components.

Figure 5. Concluded.

acting normal to the engine centerline whenever the nozzle is vectored into the free stream; it is independent of power setting. The entrainment-induced force, Fent, arises from free-stream airflow that is imparting momentum to the nozzle as a result of the engine exhaust flow. Limited Langley subscale model wind tunnel data were incorporated to provide an estimate of the total external vector force. ${ }^{3}$ No distinction between the aerodynamic flap and entrainment-induced forces is made in the NC model and only a total external force is modeled. Like the wind tunnel data from which it is derived, the simplified $\mathrm{NC}$ model is only valid for $0^{\circ}$ of angle of attack and sideslip. To summarize, the total vector force is mathematically represented as follows:

$$
F v=(F d j+F i n d)+(\text { Faero }+ \text { Fent })
$$

The NC also limits vector and area ratio requests to the load-carrying capability of the divergent actuators. The algorithm limits maximum vector angle and the amount of area ratio modulation below optimum to ensure that predicted divergent actuator loads are not exceeded. This limiting occurs in the far right-hand side of the flight envelope and only in the augmented power range.

\section{Aircraft Measurements}

The aircraft was fitted with a flight research instrumentation package that recorded over 3000 analog and digital signals. Most of these signals were also transmitted to the control room for real-time monitoring by the research team. The aircraft instrumentation system recorded the production standard measurements of engine variables such as pressure, temperature, and fuel flows. Many measurements are taken from the MUX including such parameters as aircraft rates, accelerations, attitude, atmospheric and flight conditions, pilot commands of stick, rudder, throttle, and switch position, and nozzle control computer parameters. The aircraft instrumentation system also recorded the production standard measurements of engine variables such as pressure, temperature, and fuel flows from the MUX. Most measurements were recorded at a rate of at least 80 samples per second.

Extensive flight test instrumentation on the left engine and nozzle measured essential parameters for nozzle performance determination. Measurements of pressure and temperature taken upstream of the nozzle convergent section supplied airflow conditions. Measurements of nozzle throat and divergent actuator positions were used to determine nozzle exit area. Measurements of the three divergent actuator positions were used to determine nozzle vector angle. Engine mounts and links transfer all propulsion system forces from the engine to the airframe, including axial net thrust, pitch and yaw vector forces, inertial and gyroscopic forces. These mounts and links were equipped with strain gage instrumentation to measure propulsion system forces. Exhaustive ground checkout and calibration testing made possible the separation of total vector and net thrust forces transferred through the mounts and links. The technique developed for reducing the strain gage measurements to propulsion system forces is more fully described in Conners and Sims. ${ }^{7}$ 


\section{Vectoring Nozzle Performance}

Parameters used to quantify and represent nozzle performance, and presented in the Results section, include vector-to-thrust force ratio, $(F v / F o)$, plume angle $\left(\delta_{p}\right)$, and vector efficiency $\left(\eta_{\nu}\right)$. When taken together these parameters relate the capability of the nozzle to deflect the engine thrust in the direction of vector in terms of exhaust plume angle and force

$F v / F o$ represents the ratio of the total vector force to the non-vectored gross thrust, Fo, respectively. The nonvectored gross thrust, Fo was determined from the NC computed value for $\mathrm{Fgr}$ while the nozzle was not vectored. An installed ground test and in-flight evaluation of the NC computed value for $F g r$ was completed. During the ground test, $\mathrm{Fgr}$ from the NC agreed within 2.5 percent of direct thrust stand measurements. A higher fidelity postflight, in-flight thrust model (IFT), was also evaluated relative to the thrust stand and found to be within 1 percent of stand measurements. ${ }^{6}$ Because of additional uncertainties in-flight, accuracy of the NC and IFT $F g r$ were less. In-flight accuracy of the IFT is considered to be within 2 percent at most flight conditions. Figure 6 shows a comparison of NC to IFT-calculated $F g r$ during negative pitch vectoring at ground static and an altitude of 30,000 ft for Mil power (Mil power ranges from $83^{\circ}$ to $88^{\circ}$ of power setting while Max power lies between $127^{\circ}$ and $130^{\circ}$ of power setting). NC to IFT $\mathrm{Fgr}$ agreement within the 2.5 percent shown in figure 5 is very good for the purposes of most postflight data reduction and standardization.

There were two sources for in-flight determination of total vector force, $F v$. First, $F v$ was determined through a series of reduction equations to translate uncompensated strain gage measurements from individual mount and link loads to total pitch and yaw vector forces. $F v$ was also available from the onboard model hosted in the NC computer.

The plume angle may be determined from the internal vector force and resulant gross thrust by the following equation:

$$
\delta_{p}=\sin ^{-1}(F i / F g r)
$$

$F i$ from the NC is really available as a recorded MUX parameter. An estimate of the strain-gage-derived $\mathrm{Fi}$ can also be made. $F i$ measured through the strain gages must be estimated by subtracting out the external vector force from the total vector force measurement. Currently, the best estimate of $F e$ is based upon the

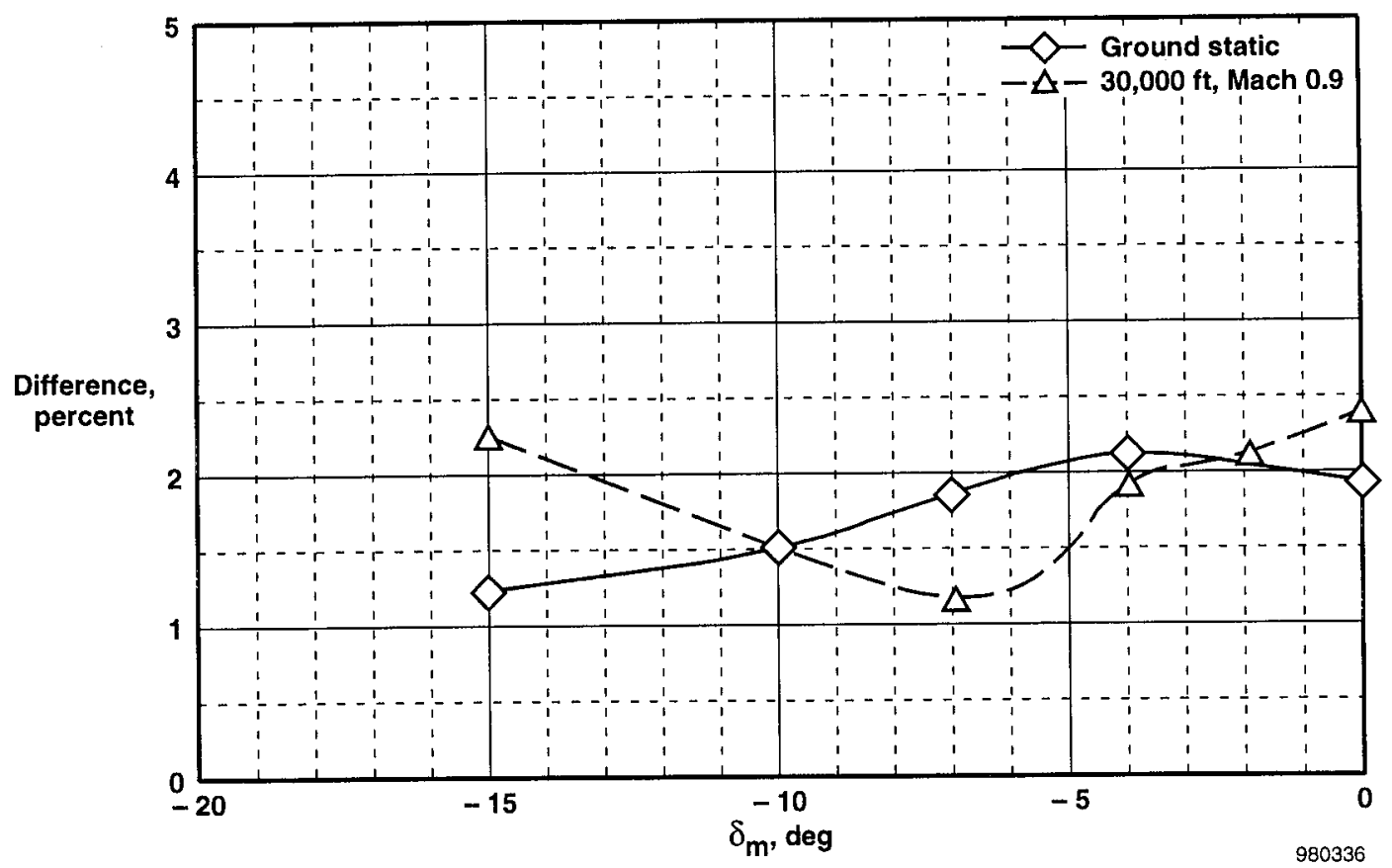

Figure 6. Resultant gross thrust comparison of the nozzle control and in-flight thrust models at Mil power. 
NASA wind tunnel data and implemented in the NC. Therefore, strain-gage-derived $F i$ is a combination of measured and calculated variables.

The vector efficiency, $\eta_{v}$, is the ratio of vector plume angle, $\delta_{p}$, to vector metal angle, $\delta_{m}$, and is expressed as a percentage of metal angle. $\eta_{v}$ values greater than 100 percent metal angle indicate flow overturning, whereas values less than 100 percent metal angle indicate flow underturning. The vector metal angle is directly measured from the NC and represents the average of the top and bottom divergent flaps. A reduction in axial thrust accompanies nozzle vectoring and is proportional to the vector metal angle. Thus, to minimize axial thrust loss, vectoring nozzles should be optimized to produce as much vector force and moment as possible for a given vector angle. This may be accomplished through maximizing the efficiency of turning of the nozzle plume.

\section{Predictions}

As previously mentioned, a study on internal nozzle performance characteristics was conducted at NASA LaRC in the static test facility of the Langley 16-Foot Transonic Tunnel. ${ }^{2}$ In an attempt to verify the pitch and yaw thrust vectoring capabilities of the multiaxis thrust vectoring axisymmetric nozzle, subscale models of fixed geometry, representing both dry and maximum afterburning power settings were tested. The results at $20^{\circ}$ of vector metal angle indicated strong flow overturning and that the vector plume angle was a strong function of NPR (fig. 7). The findings of this study were heavily relied upon for development of the NC software vector force model and flight test plan design.

\section{Flight Test Planning}

\section{Test Plan}

A nozzle performance test plan was developed to guide the research and is described. Flight data shown in this report represent only a limited portion of the data expected to be collected through the execution of this plan (fig. 8). Flight test conditions were selected to span a large range of NPR, dynamic pressure, Mach number, and ambient pressure, as shown in figure 8 . Testing includes standard configurations of power setting and vector angle at each condition. Power settings include a low power of $43^{\circ}$, maximum non-augmented power setting of $85^{\circ}$ (Mil), a mid afterburner power setting of $110^{\circ}$ (at Mach 0.9), to a maximum afterburner power setting of $130^{\circ}$ (Max). Vector angle break points include deflections of $-20^{\circ},-10^{\circ},-7^{\circ},-4^{\circ}$, and $-2^{\circ}$ while nonvectored testing occurs between vectoring tests. Other tests include variations in nozzle area ratio while vectoring, and symmetry tests in pitch and yaw.

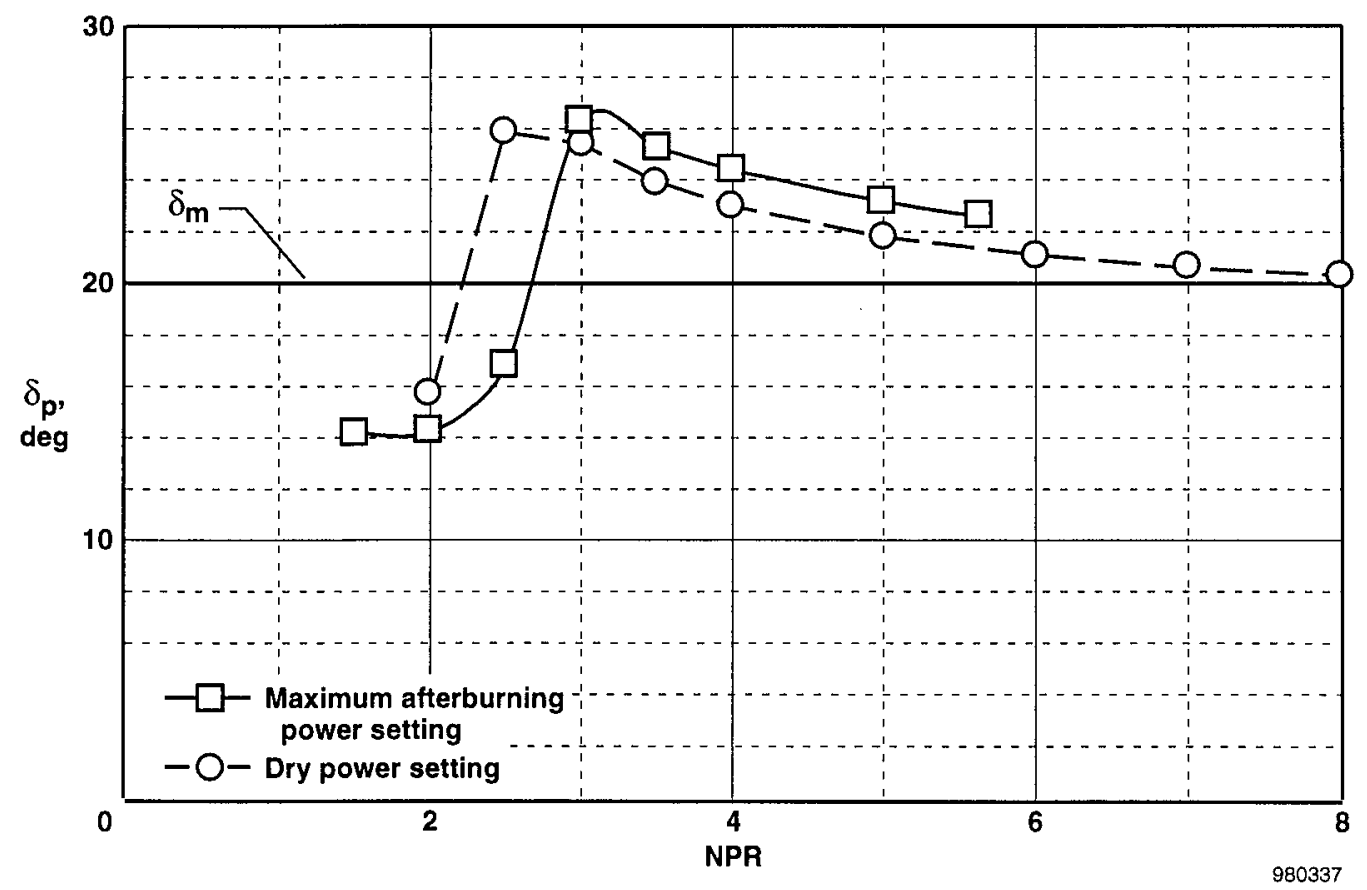

Figure 7. Subscale nozzle plume angle results at maximum afterburning and dry power settings for $20^{\circ}$ of pitch vector angle. 


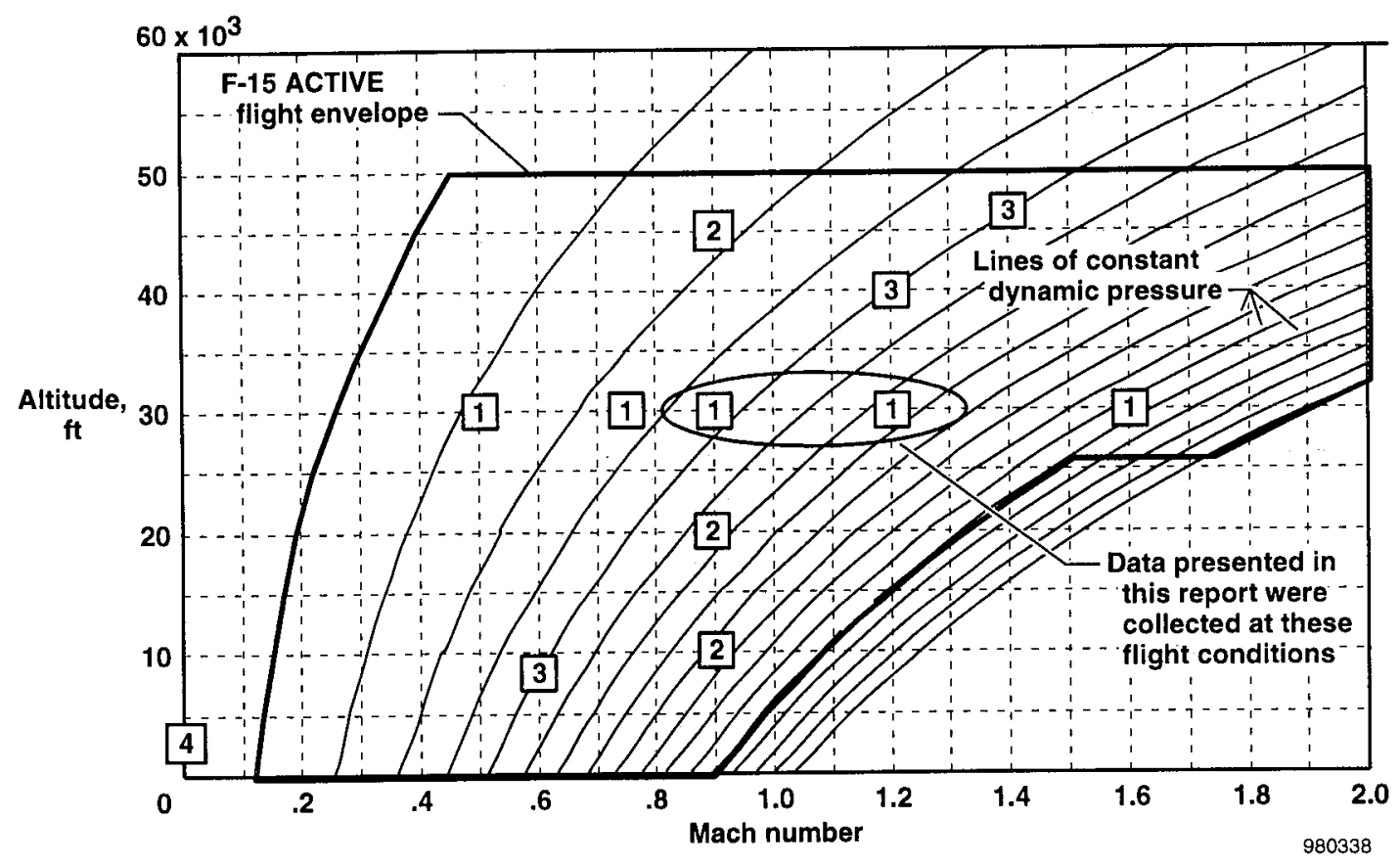

Figure 8. Nozzle performance flight test matrix.

Because of the number of variables, testing of all possible configurations and conditions is beyond the scope of the program and impractical. Initial tests evaluate the effects of test technique on data repeatability so that most data are collected with a consistent technique. Baseline testing, that is negative deflection pitch vector tests with the scheduled area ratio at an altitude of $30,000 \mathrm{ft}$, is of highest priority to establish nozzle performance. Nozzle pressure ratio ranges from near 5 to over 10 at an altitude of $30,000 \mathrm{ft}$, depending on power setting and Mach number. Tests designed to measure nozzle performance with various ambient pressures, by flying at different altitudes with the same Mach number, are of high priority. Nozzle testing at off-design area ratio, at low power settings, at constant dynamic pressure, or with yaw and positive pitch vector deflections are considered to be of lower priority.

\section{Data Reduction and Analysis}

\section{Data Reduction}

Approximately 1 to 1.5 seconds ( 80 to 120 samples of data) were used for most test points; mean values were used in all computations. The parameters were reviewed during the test point to determine when a quasi-steady state aircraft and engine condition had been reached. The parameters that have proven best to accomplish this are normal load factor and divergent actuator position. Based on this review, the same time interval segment for each parameter is averaged to represent the steady state conditions of that data point. Each of these averaged data points are then recorded in the P/YBBN performance database.

For vectoring test points, strain-gage-derived $F v$ required bias corrections to remove apparent vector force when the nozzle was not vectoring. The time trace of $F v$ from a step and hold waveform shown in figure 9 illustrates the bias correction. Although the method of obtaining the strain-gage derived $F v$ was designed to eliminate non-vector forces, biases still exist. These residual biases may arise from the applied forces such as external airloads and inertia loads. Time-averaged data were taken prior to, and after, vectoring deflections to establish the zero vector bias on $F v$.

Table 2 presents some of the parameters extracted from the raw flight test database and nominal standard deviations during the steady-state segment used for data point averaging. These standard deviations are not to imply this is the accuracy of the flight test data, but to show how little variation there was during the selected quasi-steady state maneuvers.

An important point is that once the correct time interval has been identified, any other flight test 


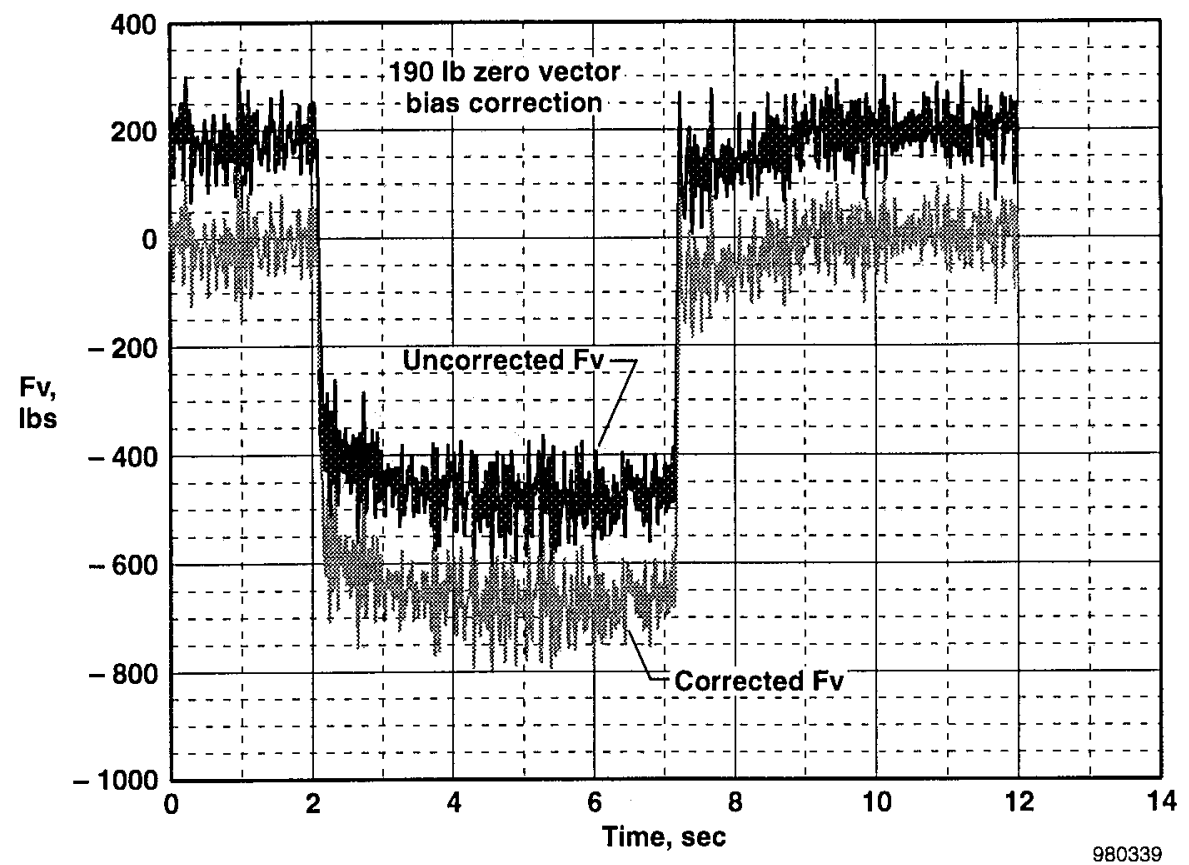

Figure 9. Zero vector bias correction and time-averaging data reduction of strain-gage-derived vector force.

parameter can be extracted from the raw flight test database and included in the P/YBBN performance database. This procedure was included to allow consideration of numerous parameters in the development of a regression model for convergent and divergent nozzle actuator loads during vectoring and nonvectoring maneuvers.

Table 2. Parameters included in the P/YBBN performance database.

\begin{tabular}{cc}
\hline \hline Variable & $\begin{array}{c}\text { Nominal standard } \\
\text { deviation }\end{array}$ \\
\hline Strain-gage-derived $F v$ & $50 \mathrm{lb}$ \\
$F g r$ & $10 \mathrm{lb}$ \\
Nozzle divergent actuator loads & $300-600 \mathrm{lb}$ \\
$F e$ & $0.2 \mathrm{lb}$ \\
Mach & 0.0005 \\
Altitude & $>5 \mathrm{ft}$ \\
$\mathrm{P}_{0}$ & $0.0001 \mathrm{psi}$ \\
$\mathrm{Tt}_{2}$ & $>0.1^{\circ} \mathrm{F}$ \\
$\delta_{m}$ & $0.02^{\circ}$ \\
Area ratio & 0.0008 \\
Throat area & $0.0006 \mathrm{sq} . \mathrm{ft}$ \\
$\mathrm{NPR}$ & 0.002 \\
$\mathrm{Pt}_{6}$ & $0.05 \mathrm{psi}$ \\
Angle of attack & $0.01^{\circ}$ \\
\hline \hline
\end{tabular}

\section{Flight Data Regression Analysis}

The NC vectoring performance model over-predicted the actual flight test vector forces by a substantial amount. A regression analysis to predict correction factors to this initial model and three variations of this model was accomplished. The purpose of this regression was to provide a tool to better predict vectoring performance and give unbiased insight into the most significant parameters that affect vectoring nozzle performance. Also, a flight-test based vectoring performance model provides help in evaluating changes to the nozzle controller software.

\section{Candidate Model Formulations}

Four different approaches for correction factors were considered in the regression analysis. In all cases, $F v$ was taken from strain-gage-derived vector force. The four different approaches are:

In the first and fourth approaches, the correction factor is an angle applied to the direct jet term. The basic difference between these approaches is the inclusion or exclusion of the internal induced force, Find, and the external vector force, $\mathrm{Fe}$, in the model formulation. All four approaches rely upon the NC modeled $F g r$, and the correction terms will reflect any $F g r$ error. In approach 1, which includes $F i n d$ and $F e$ taken from the onboard NC model, the angle correction 
$\left(\theta_{\text {corr } 1}\right)$ will reflect any errors in modeled Find, Fe, and $\mathrm{Fgr}$.

\section{APPROACH 1}

$$
F g r \sin \left(\delta_{m}-\theta_{\text {corr } 1}\right)+F i n d+F e=F v
$$

In approach 2, the correction factor is a force $\left(F_{c o r r}\right)$. The assumption here is that we understand the direct jet term, so combine all differences into a single catch-all correction force.

APPROACH 2

$$
F g r \sin \left(\delta_{m}\right)+F_{c o r r}=F v
$$

In approach 3, the correction factor is a new concept-vector force effectiveness $\left(\mu_{f}\right)$. The definition of this parameter turns the equation for approach 3 into unity.

\section{APPROACH 3}

$$
F g r \sin \left(\delta_{m} \times \mu_{f}\right)=F v
$$

where $\mu_{f}$ is the vector force effectiveness $=\left(\delta_{f} / \delta_{m}\right)$

and $\delta_{f}$ is for force angle $=\operatorname{arc} \sin (F v / F g r)$

By omitting Find and $\mathrm{Fe}$ in the model formulation of approach 4 , the angle correction $\left(\theta_{\text {corr } 4}\right)$ will reflect the total contribution of these two vector forces to $F v$. Both approach 1 and 4 models were formulated for consideration, because at this time the accuracy of the modeled $F$ ind and $F e$ is not known.

\section{APPROACH 4}

$$
F g r \sin \left(\delta_{m}-\theta_{c o r r 4}\right)=F v
$$

\section{Process and Tools Description}

A statistical software package is used to develop the initial regression model for each approach. The actual correction factor for each approach is calculated to make the left-hand side of the equation equal the righthand side, the actual measured vector force. Mathematical transformations for each parameter are also included, such as the second, third, and fourth power of the term, the reciprocal of the term, cross products with each other parameter, the square root of the term, etc. All of these new independent parameters are used in a forward stepwise regression to calculate a predicted correction factor. In a forward stepwise regression, an analysis of variation (ANOVA) is calculated on all independent variables and identifies the independent variable which most contributes to predicting the dependent variable (in this case the predicted correction factor). This independent variable is included in the model and a new ANOVA is calculated to identify the next most important independent variable. This process continues until no independent variable can satisfy the statistical tests to be included in the regression. Two statistical tests are used in the ANOVA. The F-test checks on the contribution of the independent variable in predicting the dependent variable. The larger the value of $F$ the better. The P-test is the probability of being wrong in concluding there is a true association between variables. A smaller value of $P$ is better. ${ }^{9}$ The cutoff values used in this regression analysis are $\mathrm{F}>4$ and $\mathrm{P}<0.05$.

The initial regression models are used on 90 percent of the P/YBBN database. (Note that Approach 3 cannot use all the data in the database because for very small metal angles, $\delta_{m}$, the vector force effectiveness, $\mu_{f}$, becomes infinite.) The remaining 10 percent of the P/YBBN database can be used as a check on the resulting regression model in two ways. First, comparisons of the actual correction factor to the predicted correction factor, for data points not used in the development of the regression model, are a check on the accuracy of the model. Secondly, the stepwise regression is repeated using all of the $\mathrm{P} / \mathrm{YBBN}$ database. A comparison of the initial regression model (using 90 percent of the database) with the final regression model (using 100 percent of the database) addresses the issue of regression model stability or robustness. If the same variables appear in the 90 percent model and the 100 percent model at a given level of model accuracy then the model is robust. A coefficient of determination $\left(\mathrm{R}^{2}\right)$ of 0.9 was chosen as the level of model accuracy because this gives an answer to the same acceptable minimum level of resolution as the measured strain gages of $\pm 100 \mathrm{lb}$. However, if new variables appear using 100 percent of the database, then the regression model is sensitive and should not be used beyond the bounds of the database. The selection criteria for the 10 percent of the data not used in the initial models was simply a random choice of data points that covered the full range of Mach numbers (Mach 0.9 and 1.2) and powersettings.

The results of comparing the 90 percent and 100 percent regression models are as follows: (1) Approach 1 and 4 are very robust. (2) Approach 2 is very sensitive to new data and (3) Approach 3 is 
moderately sensitive. In the case of approach 3, new independent variables appear in the best model possible $\left(R^{2}=0.94\right)$ but at the $R^{2}=0.9$ level the same independent variables are in the 90 percent and the 100 percent regression models.

\section{Discussion of Results}

\section{Description of Data Sample}

Data presented here were collected at an altitude of $30,000 \mathrm{ft}$ and Mach numbers of 0.9 and 1.2 for the baseline performance objective A1. Tests covered 4 power settings including maximum afterburner, from minimum to maximum nozzle throat area and vector angle, and at scheduled and off-scheduled nozzle exit areas.

Data were not collected beyond $-10^{\circ}$ at maximum afterburner and $-16.5^{\circ}$ at $112^{\circ}$ power settings because of NC limiting. The NC model predicted the $4000 \mathrm{lb}$ vector force limit was achieved at these angles.

\section{Nozzle Performance Results}

The nozzle performance of the pitch-vectored nozzle at Mach 0.9 is shown in figure 10. All power settings displayed similar plume deflection results (fig 10(a)); the plume was deflected less than the nozzle metal and the difference increased with increased metal angle. At maximum afterburner power setting, the plume angle decreased rapidly with increased metal angle, reaching only $-5^{\circ}$ plume angle at $-10^{\circ}$ of metal angle. For any given metal angle, the plume approaches the metal deflection as power setting is decreased.

All 4 power settings exhibited similar trends in vector efficiency (fig. 10(b)); the efficiency was decreased at small nozzle metal angles and increased with larger metal angles until reaching an apparent limit. At Mil power setting, an efficiency limit of approximately 75 percent of vector metal angle was reached near $-20^{\circ}$ of metal deflection. The same 75 percent $\eta_{v}$ limit was reached at only $-10^{\circ}$ metal angle for $54^{\circ}$ power setting. At the mid afterburner power setting of $112^{\circ}$, a maximum efficiency of about 65 percent was achieved, and at maximum afterburner the greatest efficiency of about 50 percent was reached near $-10^{\circ}$.

The vector-to-thrust ratio trends were similar for all power settings (fig $10(\mathrm{c})$ ); $F v / F o$ increased in a nearly linear manner with increased nozzle metal deflection. $F v / F o$ increased from 0 percent at nonvectored nozzle deflections to nearly 30 percent at $-20^{\circ}$ deflection at Mil power. There is close agreement between $F v / F o$ values for all power settings at any given metal angle. For example, at $-10^{\circ}$ of metal deflection, from $54^{\circ}$ to

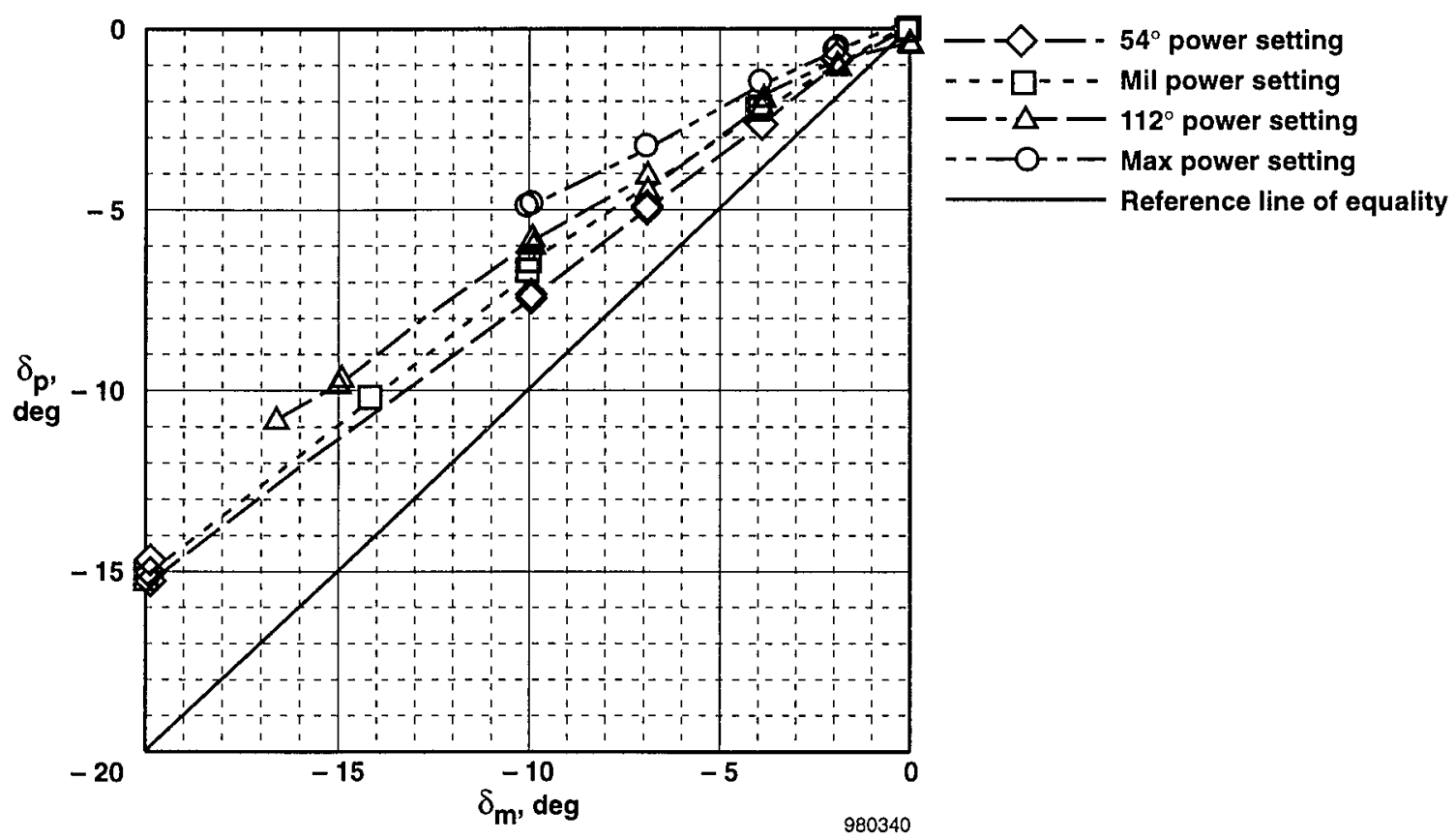

(a) Plume angle, $\delta_{p}$, as compared with metal angle, $\delta_{m}$.

Figure 10. Nozzle performance results at Mach 0.9 and an altitude of 30,000 ft. 


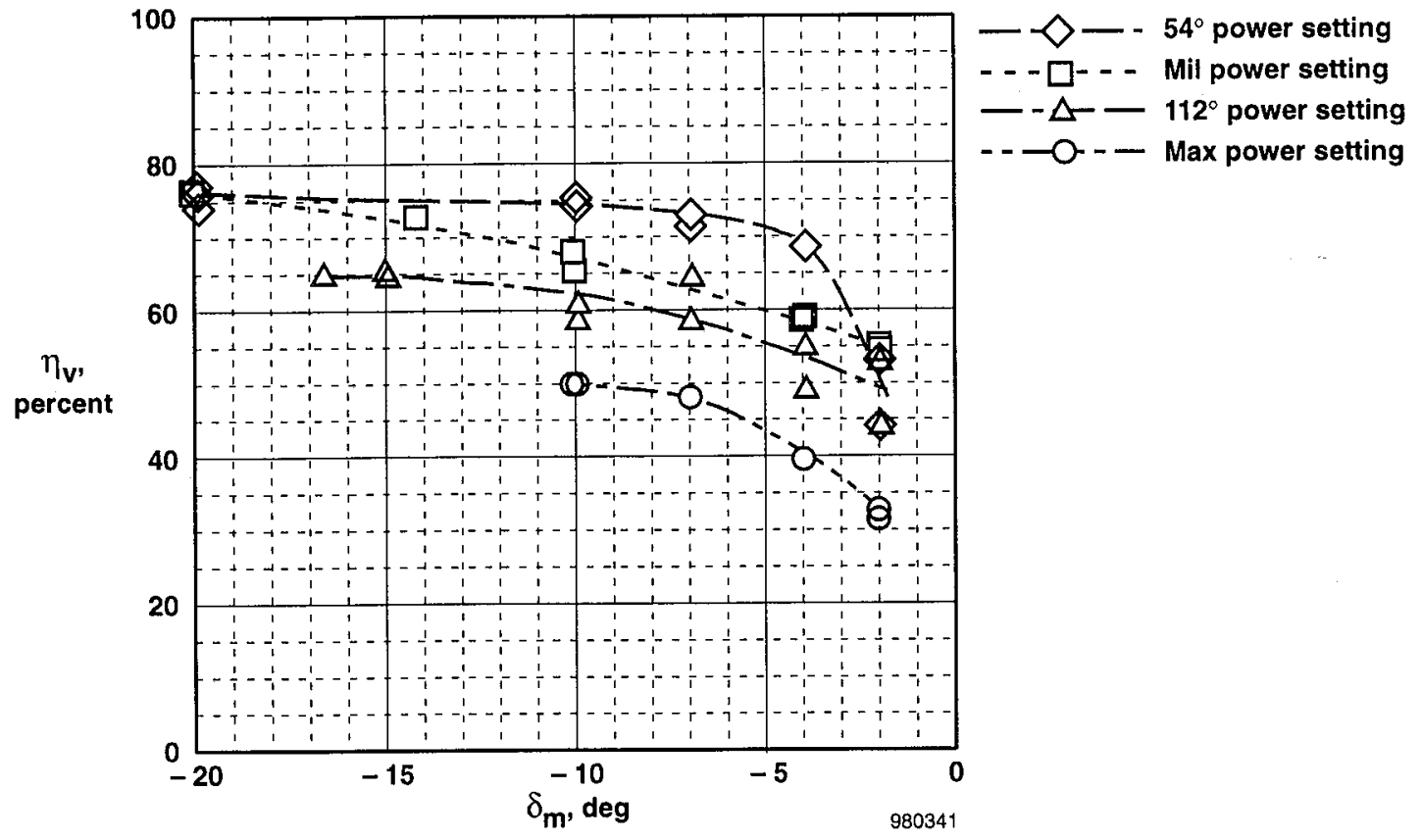

(b) Vector efficiency, $\eta_{\nu}$, as compared with metal angle, $\delta_{m}$.

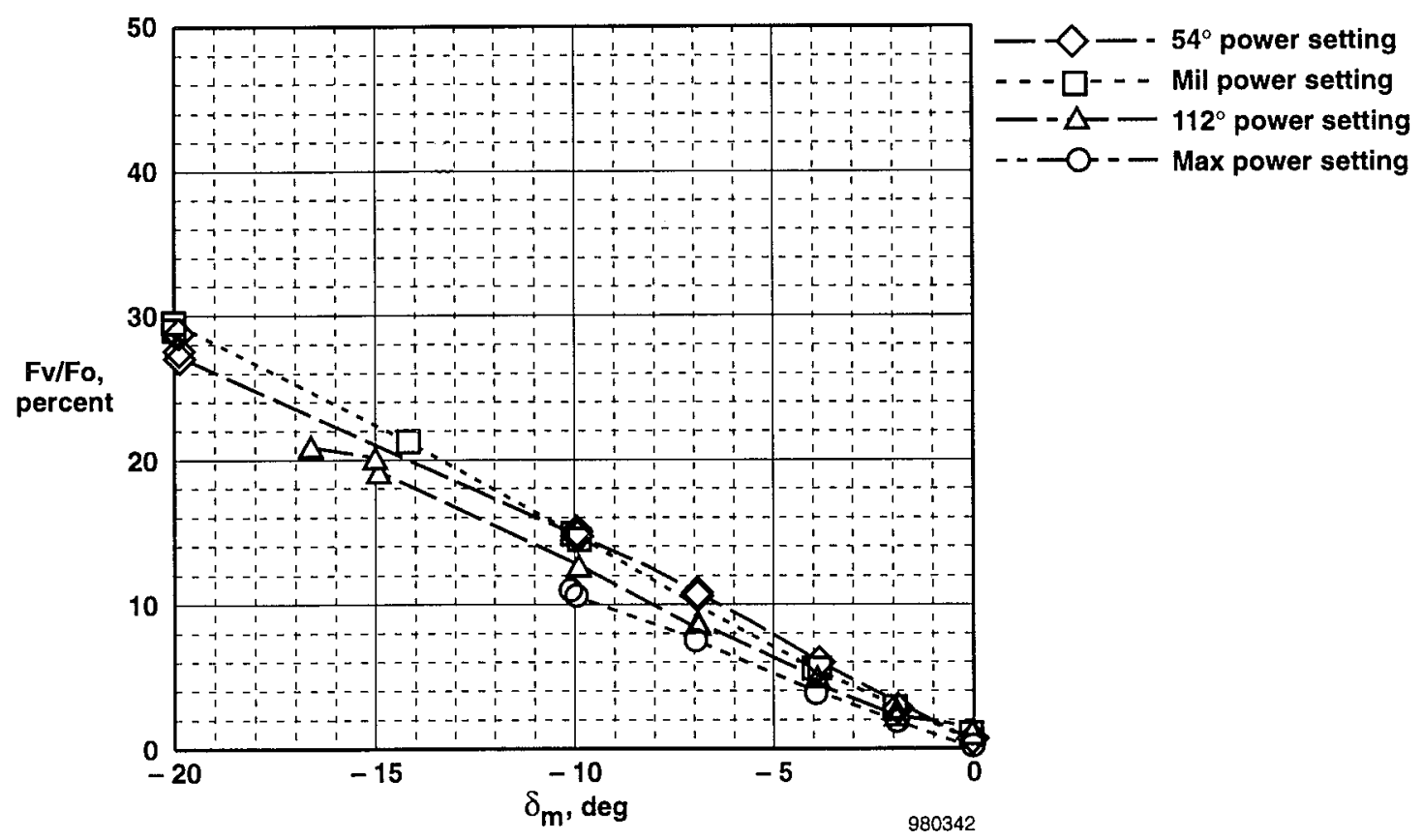

(c) Vector-to-thrust force ratio, $F v / F o$ as compared with metal angle, $\delta_{m}$.

Figure 10. Concluded. 
maximum afterburner power settings, $F v / F o$ values span less than a 5 percent band.

Overall, the flight test results indicate nozzle performance to be a strong function of both power setting and vector metal angle. The most efficient vectoring occurs at the lowest power settings with vector deflections beyond $-10^{\circ}$. Vector efficiency, $\eta_{v}$, is proportional to vector metal angle but only up to some maximum attainable limit. This limit is inversely proportional with power setting. Not only is the $\eta_{\nu}$ limit inversely proportional to power setting, but $\eta_{v}$ is also proportional to vector metal angle.

As vector metal angle increases, one side of the nozzle is deflected further into the exhaust flow and experiences increased pressure. Conversely, the opposite side of the nozzle has a relatively lower pressure that decreases as the nozzle is further deflected. Too much low pressure or suction could lead to flow separation under the right set of conditions. If the contribution to the vector force is greatest by the highpressure side of the nozzle, this may explain the increased vector efficiency with increased nozzle deflection. However, it is difficult to substantiate this hypothesis without internal pressure instrumentation. As for the reduced efficiencies at lower angles, this may be a result of taking percentages of small numbers near zero.

As power settings increase from $54^{\circ}$ to maximum afterburner, the nozzle throat area and area ratio both increase to maintain scheduled engine pressure ratio and nozzle pressure ratio. Additionally, the exhaust flow properties of pressure and temperature change as power is increased. Changes in either the nozzle geometry or flow properties may explain the trends in vector efficiency seen with power setting. The limited scope of data makes it difficult to substantiate this hypothesis at this time. However, the regression results presented next provide insight into these effects.

One possible source of error affecting the plume angle and the vector efficiency results is the modeled external vector forces. However, the magnitude of $F e$ is expected to be significantly less than the internal forces, especially at Mach 0.9 and an altitude of 30,000 ft. Once again, it is difficult to assess the accuracy of the $F e$ model without additional external pressure instrumentation or additional testing.

\section{$\underline{\text { Regression Fit Results }}$}

The $\mathrm{P} / \mathrm{YBBN}$ vectoring database is still being developed. However, even with the limited number of flight conditions some interesting trends are emerging from regression analysis. At the same level of regression model accuracy $\left(\mathrm{R}^{2}=0.9\right)$, the nozzle hardware geometry dominates the vectoring performance. In approach 1 and 4 the correction term is an angle which corrects the direct jet force term. With both approaches the correction angle is a function of the feedback nozzle vector angle and the nozzle exit area. In approach 2 , the correction term is a force that is a function of the commanded vector angle, nozzle pressure ratio, actuator load 1 , and the radius of the nozzle exit area. In approach 3, the correction term is vector force effectiveness which is a function of altitude, radius of the nozzle exit area, nozzle area ratio, actuator load 1 , nozzle exit area, feedback nozzle vector angle, and commanded nozzle vector angle. Note that in each of these regression models, the important parameters include vector angle (feedback, commanded, or both), and nozzle exit area. Because exit area is directly related to power setting, the regression results seem to substantiate the data trends and the hypothesis that the effect of power setting on vector efficiency is related to nozzle geometry.

\section{Comparisons With Predictions}

The plume angle results for a $-10^{\circ}$ pitch-vectored nozzle from the $\mathrm{NC}$ model and the strain gage are shown as a function of nozzle pressure ratio in figure 11 . Only nozzle configurations that were tested in NASA LaRC's static test facility are considered, one of which was a dry power nozzle at an area ratio of 1.35 . As previously noted in the "Vectoring Nozzle Performance" section under "Predictions", $\delta_{p}$ from the NC represents the tabular format of the CFD predictions that were matched with the LaRC data. Therefore it is not surprising that $\delta_{p}$, as predicted by the NC, is overturned at all NPR; whereas the flight measured result shows flow underturning to occur at all NPR. The largest difference between the NC model and flight measured $\delta_{p}$ is at the lowest NPR where the greatest amount of flow overturning is modeled to occur. The results show that the plume from the NC shows a strong trend with NPR like the tunnel results; the greatest $\delta_{p}$ of about $-15^{\circ}$ occurred at the lowest NPR, about 3.75. As the NPR increased, $\delta_{p}$ from the NC decreased to approximately $-12^{\circ}$. In contrast to the $\mathrm{NC}$ result, the flight results show less than a $1^{\circ}$ variation from $-7^{\circ}$ measured $\delta_{p}$ across the NPR range.

Given the number of variables and the limits of inflight measurements, it is difficult to precisely identify what accounts for the large differences between the 


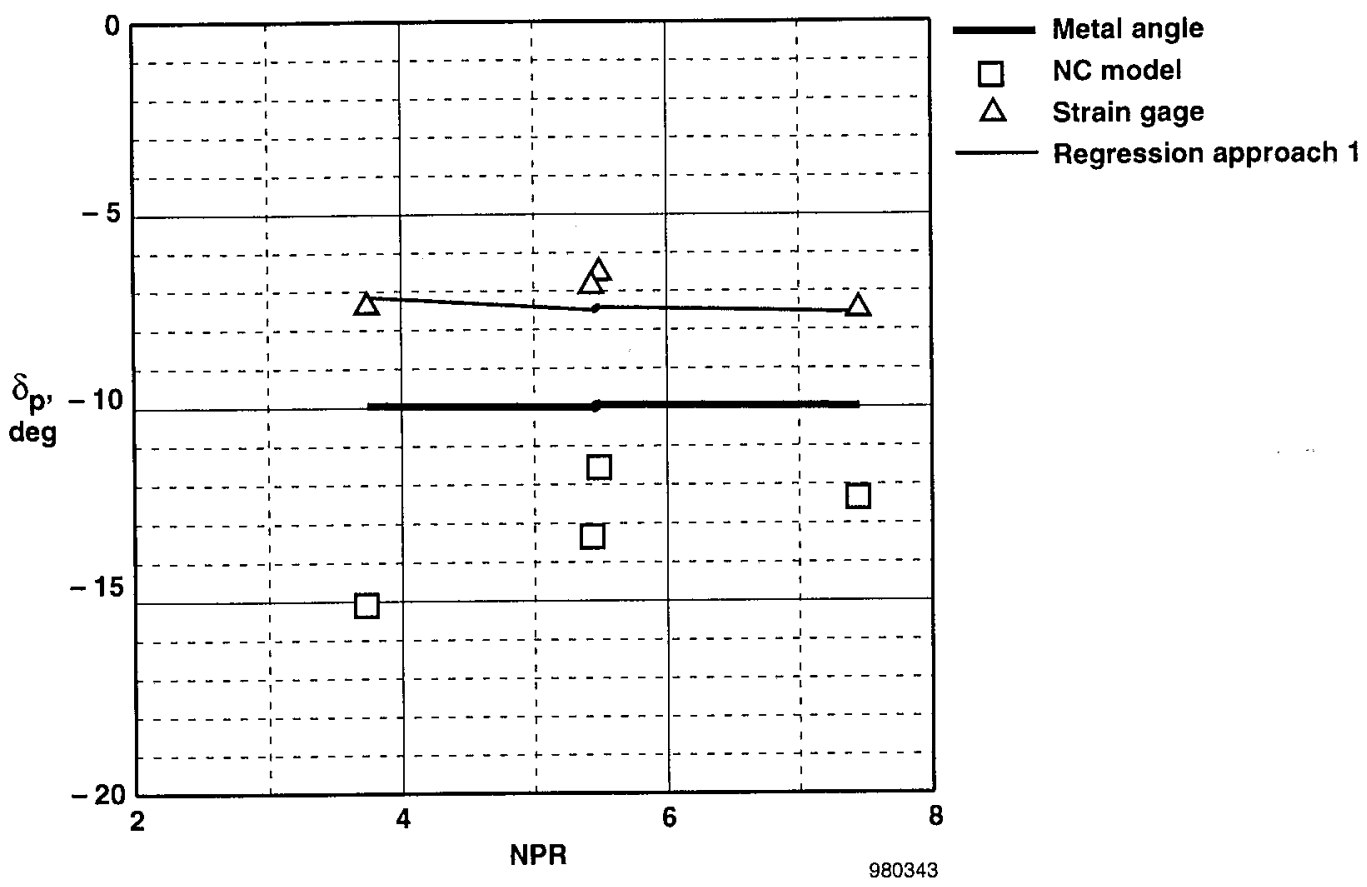

Figure 11. Comparison of modeled and measured vector turning results for a $10^{\circ}$ pitch vectored nozzle at dry power, 1.35 area ratio, at an altitude of 30,000 ft and Mach numbers of 0.9 and 1.2.

predicted nozzle performance and the measured nozzle performance. However, the sources of the difference may be classified into either nozzle geometry or flow properties. The wind-tunnel-tested nozzle was of approximately $1 / 12^{\text {th }}$ scale, contained minimal surface imperfections and lacked any potential for flow leakage. The 16 flaps that make up the gas path boundary for P/YBBN have greater roughness than the milled subscale nozzles. Additionally, the cross section of the nozzle is not perfectly circular, but rather more like a polygon made up of the 16 flaps and seals. The potential exists for flow leakage between the flaps and seals. The many details of the P/YBBN geometry open up the possibility for complex flow phenomena, including shock and boundary layer interaction or flow separation. The air flowing through the subscale nozzle was a cold flow of standard air composition, including near sea level ambient pressure into which the nozzle exhaust flowed. On the other hand, the air flowing through the $\mathrm{P} / \mathrm{YBBN}$ is made up of combustion products at temperatures that may exceed $1000^{\circ} \mathrm{F}$. Also, the flight article exhaust flowed into whatever back pressure existed at the testing altitudes. Given the number and extent of differences between the flight article and the wind tunnel or CFD-modeled nozzle, the lack of good agreement between predicted and measured nozzle performance is not surprising. This comparison of predicted with measured performance clearly illustrates the value of flight research in exploring and validating wind tunnel and CFD results, to separate the real from the imagined.

\section{Conclusions and Recommendations}

Preliminary flight test research has been conducted on the F-15 ACTIVE aircraft to determine the vectoring performance of an axisymmetric, convergent-divergent nozzle with variable throat area, exit area, and multiaxis vectoring. Comparisons are made for select conditions with CFD and wind tunnel performance predictions. The nozzle was tested with variable expansion ratios ranging from 1.06 to 1.67 and over a range of nozzle pressure ratios (NPR) including underand over-expanded flows up to $7.5 \mathrm{NPR}$. The primary test parameter was nozzle geometry. For the limited cases studied, an analysis of the research results suggests the following conclusions:

1. Vector efficiency is strongly influenced by power setting and vector metal angle.

2. CFD-based predictions and wind tunnel results are in good agreement with each other, but do not correlate well with flight test results. 
3. Flight research shows that the nozzle performance is more strongly influenced by geometry, rather than by flow properties as predicted.

4. Nozzle pressure ratio is not the major factor influencing vector plume angles.

5. Vector plume angles are usually less than the vector metal angle.

6. Nozzle efficiency is proportional to vector metal angle and inversely proportional to power setting.

7. An apparent limit on maximum nozzle efficiency is inversely proportional to power setting.

The F-15 ACTIVE open-loop architecture has been extremely valuable for the collection of high quality, repeatable data. It has allowed significant conclusions to be discovered relative to full-scale vectoring nozzle performance and emphasized the importance of flight research.

The following are specific recommendations:

1. Make a control law change to the nozzle control computer that updates the original vector force model to more accurately reflect the flight-measured vector forces, thus allowing for higher metal angles to be achieved.

2. Design and install internal and external pressure and temperature instrumentation on the divergent section of one nozzle to assist in understanding the complexities of the vectoring exhaust plume and make comparisons with predictions.

3. Expand the nozzle performance database to include more flight conditions.

\section{$\underline{\text { References }}$}

${ }^{1}$ Doane, P., R. Bursey, and G. S. Schkolnik, F-15 ACTIVE: A Flexible Propulsion Integration Testbed, AIAA 94-3360, June 1994.
${ }^{2}$ Carson, George T., Jr. and Francis J. Capone, Static Internal Performance of an Axisymmetric Nozzle with Multiaxis Thrust-Vectoring Capability, NASA TM-4237, February 1991.

${ }^{3}$ Wing, David J. and Francis J. Capone, Performance Characteristics of Two Multiaxis Thrust-Vectoring Nozzles at Mach Numbers up to 1.28, NASA TP-3313, May 1993.

${ }^{4}$ Silhavy, Robert Edward, Dual Flow Performance of $10^{\circ}$ Thrust Vectored Axisymmetric Nozzles With Varying Area Ratios, California Polytechnic State University, San Luis Obispo, California, Master's Thesis, December 1996.

${ }^{5}$ Kidman, David S., Jesse E. Vickers, and Brian P. Olson, Evaluation of The F-16 Multi-Axis Thrust Vectoring Aircraft, AFFTC-TR-95-12, September 1995.

${ }^{6}$ Smolka, J. W., et al, F-15 ACTIVE Flight Research Program, Fortieth Symposium Proceedings of the Society of Experimental Test Pilots, ISSN 0742-3705, September 1996.

${ }^{7}$ Conners, Timothy and Robert Sims, Full Flight Envelope Direct Thrust Measurement on a Supersonic Aircraft, AIAA-98-3872, July 1998.

${ }^{8}$ Crawford, Mark, Brian Hobbs, Steven Roell, and Gerard Schkolnik, STOL/Maneuver Technology Demonstrator Flying Qualities and Integrated Flight/Propulsion Control System Evaluation, Final Report, AFFTC-TR-91-29, December 1991.

${ }^{9}$ Draper, N. R. and H. Smith, Applied Regression Analysis, Second Edition, John Wiley \& Sons, Inc., New York, New York, 1981. 
Public reporting burden for this collection of information is estimated to average 1 hour per response, including the time for reviewing instructions, searching existing data sources, gathering and maintaining the data needed, and completing and reviewing the collection of information. Send comments regarding this burden estimate or any other aspect of this collection of information, including sugestions for reducing this burden, to Washington Headquarters Services, Directorate for Information Operations and Reports, 1215 Jetterson Davis Highway, Suite 1204 , Arlington, VA 22202-4302, and to the Office of Management and Budget, Paperwork Reduction Project (0704-0188), Washington, DC 20503.

\begin{tabular}{|l|l|l|}
\hline 1. AGENCY USE ONLY (Leave blank) & $\begin{array}{c}\text { 2. REPORT DATE } \\
\text { July } 1998\end{array}$ & $\begin{array}{l}\text { 3. REPORT TYPE AND DATES COVERED } \\
\text { Technical Memorandum }\end{array}$ \\
\hline
\end{tabular}

4.TITLE AND SUBTITLE

July 1998

Technical Memorandum

Initial Flight Test Evaluation of the F-15 ACTIVE Axisymmetric

Vectoring Nozzle Performance

6. AUTHOR(S)

WU 529-50-40-00-32-00-001

John S. Orme, Ross Hathaway, and Michael D. Ferguson

7. PERFORMING ORGANIZATION NAME(S) AND ADDRESS(ES) REPORT NUMBER

NASA Dryden Flight Research Center

P.O. Box 273

$\mathrm{H}-2267$

Edwards, California 93523-0273

9. SPONSORING/MONITORING AGENCY NAME(S) AND ADDRESS(ES)

10. SPONSORING/MONITORING AGENCY REPORT NUMBER

National Aeronautics and Space Administration

Washington, DC 20546-0001

NASA/TM-1998-206558

\section{SUPPLEMENTARY NOTES}

Presented at the 34th AIAA/ASME/SAE/ASEE Joint Propulsion Conference, Cleveland, Ohio, July 13-15, 1998. John S. Orme, NASA Dryden Flight Research Center, Edwards, California; Ross Hathaway, Analytical Services \& Materials,

Edwards, California; Michael D. Ferguson, United Technologies Corporation, Pratt \& Whitney, West Palm Beach, Florida.

\begin{tabular}{|l|l}
\hline 12a. DISTRIBUTIONAVAILABILITY STATEMENT & 12b. DISTRIBUTION CODE
\end{tabular}

Unclassified-Unlimited

Subject Category 05, 07

13. ABSTRACT (Maximum 200 words)

A full envelope database of a thrust-vectoring axisymmetric nozzle performance for the Pratt \& Whitney Pitch/Yaw Balance Beam Nozzle (P/YBBN) is being developed using the F-15 Advanced Control Technology for Integrated Vehicles (ACTIVE) aircraft. At this time, flight research has been completed for steady-state pitch vector angles up to $20^{\circ}$ at an altitude of $30,000 \mathrm{ft}$ from low power settings to maximum afterburner power. The nozzle performance database includes vector forces, internal nozzle pressures, and temperatures all of which can be used for regression analysis modeling. The database was used to substantiate a set of nozzle performance data from wind tunnel testing and computational fluid dynamic analyses. Findings from initial flight research at Mach 0.9 and 1.2 are presented in this paper. The results show that vector efficiency is strongly influenced by power setting. A significant discrepancy in nozzle performance has been discovered between predicted and measured results during vectoring.

14. SUBJECT TERMS

15. NUMBER OF PAGES

Axisymmetric nozzle, Convergent-divergent nozzles, Flight test, Internal performance, Mechanical thrust vectoring, Thrust Vectoring,

24

16. PRICE CODE

$\mathrm{A03}$

17. SECURITY CLASSIFICATION

OF REPORT

Unclassified

18. SECURITY CLASSIFICATION
OF THIS PAGE
Unclassified

19. SECURITY CLASSIFICATION
OF ABSTRACT
Unclassified

NSN 7540-01-280-5500

20. LIMITATION OF ABSTRACT
Unlimited

